\title{
The Effects of Inflammatory Tooth Pain on Anxiety in Adult Male Rats
}

\author{
Maryam Raoof ${ }^{1}$, Hamed Ebrahimnejad ${ }^{2 *}$, Mehdi Abbasnejad ${ }^{3}$, Ladan Amirkhosravi ${ }^{4}$, Ramin Raoof ${ }^{4}$, Saeed Esmaeili Mahani $^{4}$, Mohsen \\ Ramazani5 $^{5}$, Noushin Shokouhinejad ${ }^{6}$, Mehrfam Khoshkhounejad ${ }^{6}$ \\ 1. Oral and Dental Diseases Research Center, Kerman University of Medical Sciences, Kerman, Iran \\ 2. Department of Oral \& Maxillofacial Radiology, Faculty of Dentistry, Mashhad University of Medical Sciences, Mashhad, Iran. \\ 3. Department of Biology, Faculty of Sciences, Shahid Bahonar University of Kerman, Kerman, Iran. \\ 4. Laboratory of Molecular Neuroscience, Neuroscience Research Center, Institute of Neuropharmacology, Kerman University of Medical Sciences, Kerman, Iran \\ 5. Department of Endodontics, Faculty of Dentistry, Mazandaran University of Medical Sciences, Mazandaran, Iran. \\ 6. Dental Research Center, Department of Endodontics, School of Dentistry, Tehran University of Medical Sciences, Tehran, Iran.
}

Cittation: Raoof, M., Ebrahimnejad, H., Abbasnejad, M., Amirkhosravi, L., Raoof, R., Esmaeili Mahani, S., et al. (2016). The effects of inflammatory tooth pain on anxiety in adult male rats. Basic and Clinical Neuroscience, 7(3), 259-268. http://dx.doi.org/10.15412/J.BCN.03070311

doif: http://dx.doi.org/10.15412/J.BCN.03070311

Article info:

Received: 08 June 2015

First Revision: 29 June 2015

Accepted: 15 October 2015
Key Words:

Odontalgia, Capsaicin, Formalin, Diazepam, Anxiety, Elevated plus maze

\begin{abstract}
A B S T RA C T
Introduction: This study aimed to examine the effects of induced inflammatory tooth pain on anxiety level in adult male rats.

Methods: The mandibular incisors of 56 adult male rats were cut off and prefabricated crowns were fixed on the teeth. Formalin and capsaicin were injected intradentally to induce inflammatory tooth pain. Diazepam treated group received diazepam 30 minutes before intradental injection. The anxietyrelated behavior was evaluated with elevated plus maze test.

Results: Intradental application of chemical noxious stimuli, capsaicin and formalin, significantly affected nociceptive behaviors $(\mathrm{P}<0.001)$. Capsaicin $(\mathrm{P}<0.001)$ and formalin $(\mathrm{P}<0.01)$ significantly increased the anxiety levels in rats by decrease in the duration of time spent in open arm and increase in the duration of time spent in closed arm. Rats that received capsaicin made fewer open arm entries compared to the control animals $(\mathrm{P}<0.05)$. Capsaicin $(\mathrm{P}<0.001)$ and formalin $(\mathrm{P}<0.01)$ treated rats showed more stretch attend postures compared to the control and sham operated animals. In diazepampretreated rats, capsaicin induced algesic effect was prevented $(\mathrm{P}<0.001)$.
\end{abstract}

Conclusion: Inflammatory pulpal pain has anxiogenic effect on rats, whereas diazepam premedication showed both anxiolytic and pain reducing effects.

\section{Introduction}

ince the beginning of humanity, pain has always been one of the major concerns of human beings and orofacial pain and odontalgia in particular is one of the most prevalent types of pain experienced by a large portion of the world's population (Lipton, Ship, \& Larach-Robinson, 1993).

Pain often co-occurs with negative psychological moods, especially anxiety (Beesdo et al., 2010). The impact of the anxiety is not only limited to consistent stress which

* Corresponding Author:

Hamed Ebrahimnejad, DDS, MSc.

Address: Department of Oral \& Maxillofacial Radiology, Faculty of Dentistry, Mashhad University of Medical Sciences, Mashhad, Iran

Tel: $+98(51) 38829501 \quad$ Fax: $+98(51) 38829500$

E-mail:raoofm56@yahoo.com_ebrahimnh911@mums.ac.ir 
is associated with higher risk of cardiovascular and cerebrovascular disease, but also has such debilitating physical manifestations as headache, uncontrolled trembling, sweating, muscle tension, and aches (Kizilbash, Vanderploeg, \& Curtiss, 2002; Rozanski, Blumenthal, Davidson, Saab, \& Kubzansky, 2005).

The association between various types of pain and anxiety has been widely evaluated (Arnold, Leon, Whalen, \& Barrett, 2010; Beesdo et al., 2010; Boleta-Ceranto, Bianchi, Miura, Veiga, \& Bremm, 2010; Kuijpers et al., 2003; Oliveira \& Colares, 2009; Schellinck, Stanford, \& Darrah, 2003). Orofacial nociceptive response induced by $1 \%$ formalin injection in superficial (lip) and deep (temporomandibular joint) orofacial regions of rats increases the anxiety level (Boleta-Ceranto, et al., 2010). Formalin is a noxious stimulus widely used in animal behavioral experiments for studying mechanisms of pain. The formalin test originally was described by Dubuisson and Dennis (1977) and consists of a subcutaneous formalin injection into the rat's hindpaw. It was further adapted for assessing pain in the superficial tissues of the orofacial region by Clavelou and associates (1995).

Dental anxiety is related to a history of dental pain in children under the age of 5 (Oliveira \& Colares, 2009). Acute repetitive pain experienced during infancy may increase anxiety later in life (Schellinck, Stanford, \& Darrah, 2003). Despite these observed relations, there is a lack of understanding of the interplay between pulpal inflammatory pain and pain-induced anxiety. Moreover, the tooth pulp has a dense sensory innervation, which conveys sensory signals perceived as pain. This innervation, which originates from the trigeminal ganglion, can be a good model for analyzing the trigeminal nociceptive behavior (Fried, Lillesaar, Sime, Kaukua, \& Patarroyo, 2007). To fill this gap in the extant literature, the present investigation sought to evaluate this relationship using the elevated plus maze test. This test is known for its high ecological validity and reliable measurement of behaviors associated with anxiety and risk assessment in rodents. Only with a precise understanding of this issue, we can achieve accurate measurement and effective intervention.

\section{Methods}

\subsection{Ethics statement}

All experimental procedures performed on rats were approved by the Animal Research Ethics Committee of Kerman University of Medical Sciences, Kerman, Iran (Permit Number: K/90/258). All efforts were made to minimize their suffering. After the assessment of pain and anxiety, if animals showed persistent pain behavior, acetaminophen $12.5 \mathrm{mg} / \mathrm{kg}$ was administered intraperitoneally.

\subsection{Animals}

Fifty-six adult male Wistar rats weighing 250-300 g, purchased from the Neuroscience Research Center (Kerman University of Medical Sciences, Iran), were used in this study. The rats were housed one per cage in a room with a temperature of $23 \pm 2^{\circ} \mathrm{C}$ where they were subjected to a regimen of 12:12 day/night cycles and unlimited access to standard rat chow and water before and during the study.

\subsection{Dental procedure}

Inflammatory pulpal pain induction was constructed based on our model, representing a modification to the Chidiac et al. (2002) study described in a previous article (Raoof, Abbasnejad, Amirkhosravi, \& Ebrahimnejad \& Raoof, 2012). In brief, the distal $2 \mathrm{~mm}$ of the rats' mandibular incisors were cut off and special polyethylene crowns were fixed on the teeth using a flow composite resin (Tetric Flow, Ivoclar Vivadent). A small space remained between the tooth structure and the internal surface of the crown. After placement of the crowns, the animals received the powder form of their food. The control group with intact teeth had the same food regimen too. In situations that the crowns were removed by an animal, it was substituted with another one.

\subsection{Study drugs}

Formalin 2.5\% (Sigma-Aldrich): Stock formaldehyde solution (an aqueous solution of $37 \%$ formaldehyde) was diluted to $2.5 \%$ formalin in isotonic saline.

Capsaicin (Sigma-Aldrich): Capsaicin was dissolved in Tween 80-ethanol solution (Merck, Germany) (10\% ethanol, $10 \%$ Tween $80,80 \%$ distilled water, $w / w)$ at concentrations of 25 and $100 \mu \mathrm{g} / \mu \mathrm{L}$ and administrated intradentally.

Diazepam (Kimidaru, Iran): Animals received intraperitoneal injections of diazepam $1 \mathrm{mg} / \mathrm{kg}$.

\subsection{Study groups}

Fifty-six animals were randomly divided into eight groups $(\mathrm{n}=7)$ as follows:

1. Control group included intact animals without polyethylene crowns;

2. Sham operated group (Sham op) intradentally received injection of normal saline; 
3. Sham vehicle group (Sham veh) intradentally received injection of capsaicin vehicle, including Tween 80 and ethanol;

4. Diazepam group included animals with polyethylene crowns, which received intraperitoneal injection of diazepam;

5, 6. Capsaicin treated groups (Cap 25 and Cap 100) received intradental injection of $25 \mu \mathrm{g} / \mu \mathrm{L}$ and $100 \mu \mathrm{g} / \mu \mathrm{L}$ capsaicin, respectively;

7. Formalin treated group intradentally received injection of formalin $2.5 \%$;

8. Diazepam treated group intraperitoneally received diazepam 30 minutes before administration of capsaicin $100 \mu \mathrm{g} / \mu \mathrm{L}$.

Two days after operation, the awake animals were immobilized in plastic holding tubes. A small retractor was used to keep the mouth open. Based on the study group, $10 \mu \mathrm{L}$ of the specified drug was injected into the chamber using a 27-gauge needle and cyanoacrylate adhesive was then used for the closure of crown perforation. Loupes with $4 \mathrm{x}$ in magnification were utilized.

\subsection{Nociceptive behavior}

Test sessions took place during the light phase, between 10:00 AM and 5:00 PM in a quiet room maintained at $23^{\circ} \mathrm{C}-24^{\circ} \mathrm{C}$. To minimize additional stress, each animal was placed in the test box for a 30-min habituation period before the injection. The rats had no access to food or water during the test.

Immediately after the injection, the rats were individually placed in the Plexiglas box $(25 \times 35 \times 35 \mathrm{~cm})$ positioned over a mirror angled at 45 degrees to allow an unobstructed view of nociceptive behavior. The rats' behavior was observed for 21 minutes, divided into 7 blocks of 3 minutes. A pain score was calculated for each block by measuring the amount of time spent in each of the following responses (Chidiac et al., 2002): A score of 0 was attributed to a normal behavior such as grooming; score 2 was considered for abnormal head movements such as continuous placement of the jaw on the cage floor or walls or mild head shaking; score 2 was assigned to abnormal continuous shaking of the lower jaw; score 3 was attributed when the animals showed consistent and excessive rubbing of the mouth with foreleg movements. Rats' behavior was recorded by a video camera.

\subsection{Elevated plus maze}

The plus maze apparatus consisted of 4 arms $(50 \mathrm{~cm} \times 10$ $\mathrm{cm}$ ) in the shape of a cross, extending off of a center square
$(10 \mathrm{~cm} \times 10 \mathrm{~cm})$ and elevated $50 \mathrm{~cm}$ from the floor. Two of the opposing arms had a small raised lip $(1 \mathrm{~cm})$ around the edges (open arms) and the remaining two arms were enclosed with $40 \mathrm{~cm}$ transparent Plexiglas walls (closed arms). The floor of the maze was made of black Plexiglas. The test room was illuminated by a $60 \mathrm{~W}$ red lamp. A video camera interfaced with a TV monitor and a VCR was used to record each trial. Rats were tested immediately after nociceptive behavior assessment using elevated plus maze. Each rat was lowered onto the central square and its behavior in the maze was video-recorded for 5 minutes for subsequent analysis (Hindsight Version 1.5 ). videos were analyzed by an observer blind to the experimental conditions for the following behaviors: (1, 2 ) the time spent by the animal in the open and closed arms; $(3,4)$ total number of entries into the open and closed arms; (5) number of stretch-attend postures; (6) frequency of head dipping; (7) time spent rearing; and (8) time spent grooming. After each trial, the entire maze was cleaned with $70 \%$ ethanol. Percentage of open arm entries and time were used as anxiety indexes (Walf \& Frye, 2007) (Walf \& Frye, 2007).

\subsection{Statistical analysis}

The effects of intradental application of chemical noxious stimuli, capsaicin and formalin, on nociceptive behaviors were determined by 1-way ANOVA followed by Tukey post hoc test. For the analysis of anxiety parameters, 1-way ANOVA followed with Tukey-Kramer multiple comparison procedures were performed with homogeneous variances. ANOVA model was adjusted for unequal variances when needed as determined by Levene's test of equality of error variances. The Welch ANOVA followed by Dunnett-test was performed with heterogeneous variances. Results are presented as mean \pm standard error. All statistical analyses were performed with SPSS 19.0 for Windows (SPSS, Inc., Chicago, IL).

\section{Results}

\subsection{Effect of intradental application of capsaicin and} formalin on nociceptive behaviors

Intradental application of chemical noxious stimuli, capsaicin $(25$ and $100 \mu \mathrm{g} / \mu \mathrm{L})$ and formalin $2.5 \%$, significantly affected nociceptive behaviors ( $\mathrm{P}<0.001)$ (Figure 1). Additionally, the data indicated that the greatest effect was obtained from capsaicin $100 \mu \mathrm{g} / \mu \mathrm{L}$. In diazepam-pretreated rats, capsaicin-induced algesic effect was prevented $(\mathrm{F}(5,41)=32.19$, $\mathrm{P}=0.001$, 1-way ANOVA).

\subsection{Effect of inflammatory tooth pain on anxiety}

Comparisons of control, sham operated, sham vehicle and diazepam control groups. One-way ANOVA revealed no 


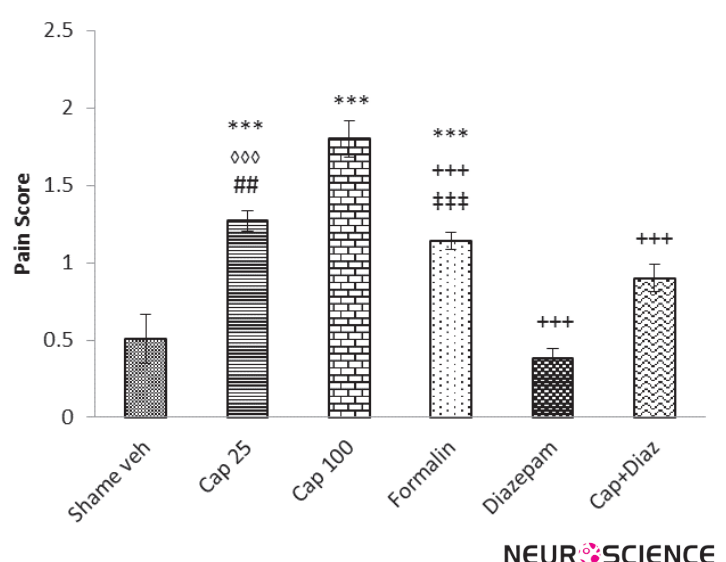

Figure 1. Nociceptive effect of intradental injection of chemical noxious stimuli, capsaicin $(25$ and $100 \mu \mathrm{g} / \mu \mathrm{L})$ and formalin $2.5 \%$.

Abbreviations: Sham op, sham operated; Sham veh, sham vehicle; Cap25, capsaicin $25 \mu \mathrm{g} / \mu \mathrm{L}$; Cap100, capsaicin $100 \mu \mathrm{g} / \mu \mathrm{L}$; Cap+Diaz, Injection of diazepam before capsaicin $100 \mu \mathrm{g} / \mu \mathrm{L}$. Values are presented as mean \pm SEM $(n=7)$.

*** $\mathrm{P}<0.001$ vs Sham veh, $\quad * * \mathrm{P}<0.01$ vs Cap 100

*** $\mathrm{P}<0.001$ vs Cap $100 \quad$ *** $\mathrm{P}<0.001$ vs Diazepam,

**P<0.01 vs Diazepam.

significant differences among intact, sham operated, sham vehicle, and diazepam control groups with respect to the behaviors scored in the elevated plus maze.

\subsection{Effect of formalin- and capsaicin-induced inflam- matory tooth pain on anxiety}

The effects of tested algesic chemicals on anxiety have been shown in Figure 2 A-F. There were significant differences between the study groups regarding the mean time spent in open arms $(\mathrm{F}(7,48)=4.24, \mathrm{P}=0.001,1$-way ANOVA). Capsaicin 25 and $100 \mu \mathrm{g} / \mu \mathrm{L}$ and $2.5 \%$ formalin significantly increased the anxiety levels in rats by decrease in the time spent in open $\operatorname{arm}(\mathrm{P}<0.05, \mathrm{P}<001, \mathrm{P}<0.01$, respectively; post hoc Tukey HSD test) and increase in time

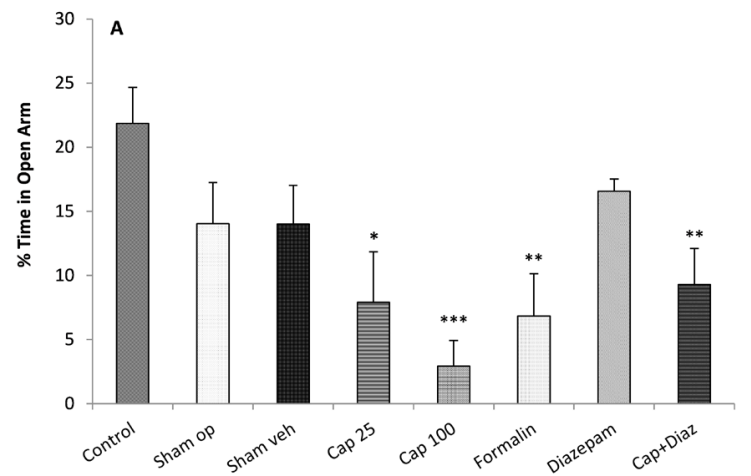

spent in closed $\operatorname{arm}(\mathrm{P}<0.01, \mathrm{P}<001, \mathrm{P}<0.01$, respectively post hoc Tukey HSD test).

There were significant differences between the study groups regarding the mean open arm entries $(\mathrm{F}(7,48)=2.45, \mathrm{P}=0.031$ Welch test). Rats that received capsaicin $100 \mu \mathrm{g} / \mu \mathrm{L}$ made fewer open arm entries compared to the control and diazepamtreated animals $(\mathrm{P}<0.01, \mathrm{P}<0.05$, respectively; Dunnett-test, Figure $2 \mathrm{C})$. However, there was no significant difference between the groups in the number of entries in closed arm $(\mathrm{F}(7$, $48)=1.93, \mathrm{P}=0.08,1$-way ANOVA) (Figure 2D).

One-way ANOVA revealed significant differences between the groups in stretch attend postures $(\mathrm{F}(7,48)=6.44, \mathrm{P}=0.000$, 1-way ANOVA) (Figure 2D). Capsaicin $100 \mu \mathrm{g} / \mu \mathrm{L}$ and $2.5 \%$ formalin treated rats showed more stretch attend postures than the control and sham operated animals $(\mathrm{P}<0.01$, post hoc Tukey HSD test). Moreover, there was no significant difference between the diazepam plus capsaicin $100 \mu \mathrm{g} / \mu \mathrm{L}$ group and the control group (Figure 2E).

Capsaicin 25 and $100 \mu \mathrm{g} / \mu \mathrm{L}$ and $2.5 \%$ formalin groups displayed fewer head dips compared to the control, sham operated ( $\mathrm{P}<0.001$, Dunnett-test) and diazepam $(\mathrm{P}<0.01$, Dunnett-test) groups indicating an anxiogenic effect, but no differences were found between the diazepam plus capsaicin $100 \mu \mathrm{g} / \mu \mathrm{L}$ group and control group (Figure $2 \mathrm{~F}$ ).

There were no significant differences between the groups regarding the time spent rearing $(\mathrm{F}(7,48)=1.31, \mathrm{P}=0.26$, 1-way ANOVA) (Figure 2G). Treatment with diazepam resulted in a significant increased grooming frequency compared to formalin and capsaicin plus diazepam groups $(\mathrm{F}(7,48)=3.282, \mathrm{P}=0.006,1$-way ANOVA $)$ (Figure $2 \mathrm{G})$.

\section{Discussion}

We found that capsaicin- and formalin-induced inflammatory pulpal pain state would lead to an anxiogenic effect in rats in the elevated plus maze by increasing stretch attends,

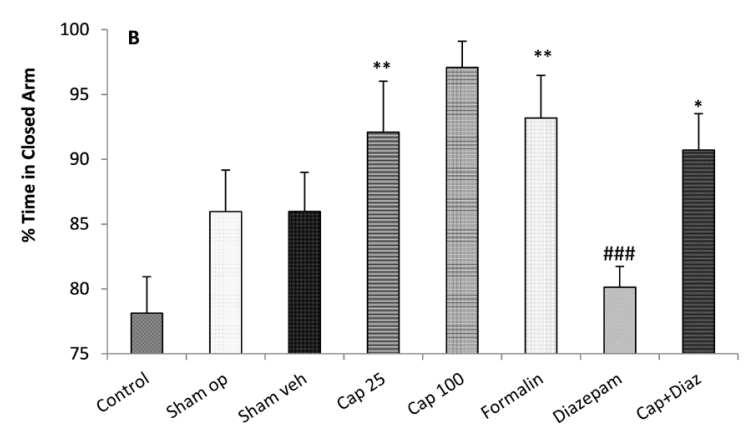



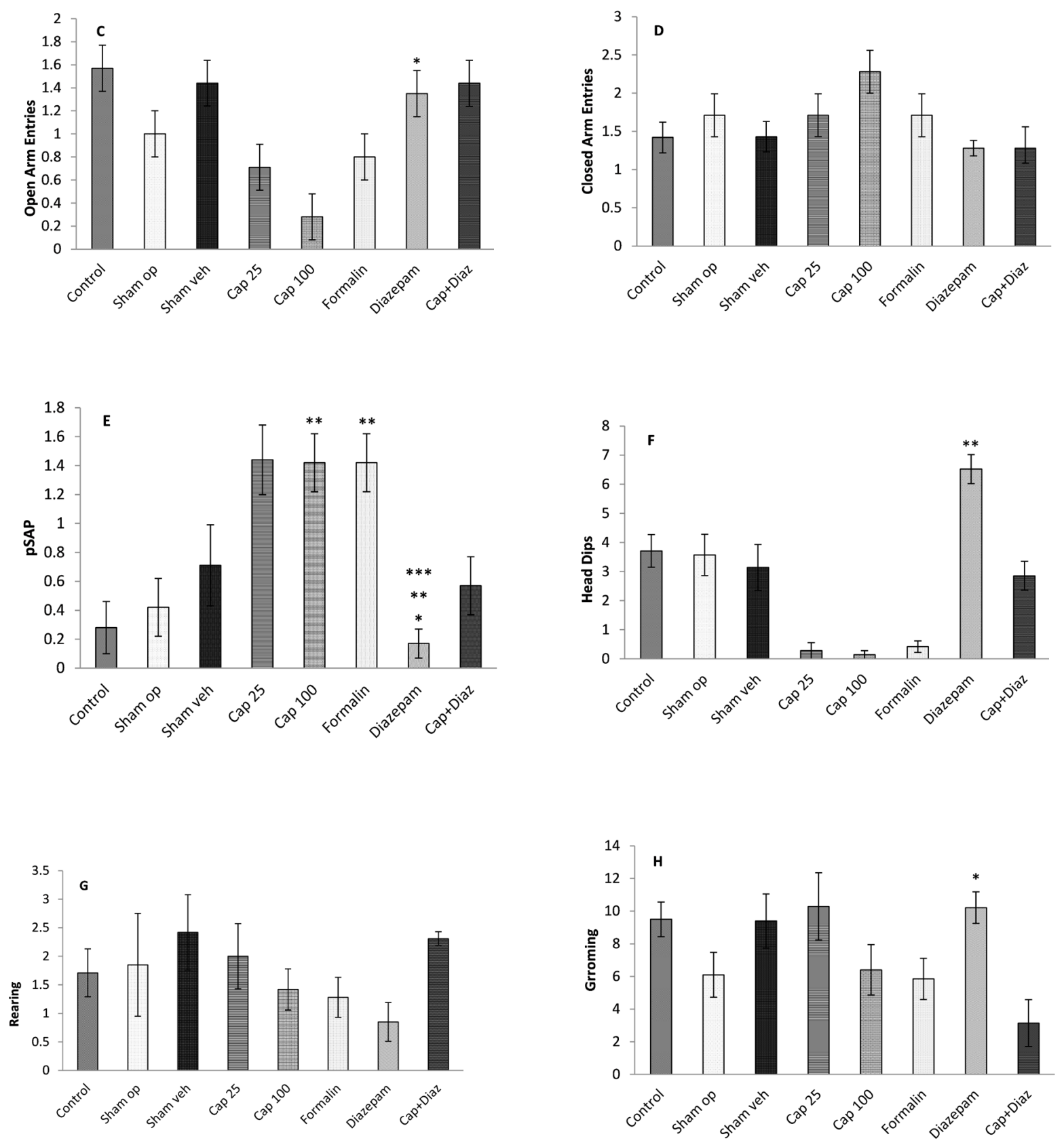

NEUR:SCIENCE

Figure 2. Effect of inflammatory tooth pain on anxiety.

Abbreviations: Sham op, sham operated; Sham veh, sham vehicle; Cap25, capsaicin 25 $\mu \mathrm{g} / \mu \mathrm{L}$; Cap100, capsaicin 100 $\mu \mathrm{g} / \mu \mathrm{L}$; Cap+Diaz, Injection of diazepam before capsaicin $100 \mu \mathrm{g} / \mu \mathrm{L} ; \mathrm{pSAP}$, Protected Stretched Attention Posture.

Values are presented as mean \pm SEM $(n=7)$.

A: ${ }^{*} \mathrm{P}<0.05 ;{ }^{* *} \mathrm{P}<0.01,{ }^{* * *} \mathrm{P}<0.01$ vs control.

B: ${ }^{* * *} \mathrm{P}<0.001$ vs Cap 25, Cap 100, Formalin and Cap+Diaz groups; ${ }^{*} \mathrm{P}<0.05$ vs control; ${ }^{* *} \mathrm{P}<0.01$ vs control; *** $\mathrm{P}<0.001$ vs control.

C: ${ }^{*} \mathrm{P}<0.05$ vs diazepam; ${ }^{*} \mathrm{P}<0.01$ vs control.

E: * ${ }^{\mathrm{P}<0.05}$ vs Cap25; ${ }^{* *} \mathrm{P}<0.01$ vs control and Sham op; ${ }^{* * *} \mathrm{P}<0.001$ vs formalin.

F: ** $\mathrm{P}<0.01$ vs control and Sham op; ${ }^{* *} \mathrm{P}<0.001$ vs control.

H: *P<0.05 vs Cap+Diaz. 
decreasing head dips and time spent in the open arms and frequency of open arm entries. This finding is consistent with a relatively large corpus of work documenting that, pain and anxiety are closely connected (Beesdo et al., 2010; Deng \& Cassileth, 2005; Ennaceur, Michalikova, \& Chazot, 2006; Friedrich, Hahne, \& Wepner, 2009; Martin \& MacLeod, 2009; McCracken, Faber, \& Janeck, 1998; Oliveira \& Colares, 2009; Pae et al., 2009; Primeaux, Wilson, McDonald, Mascagni, \& Wilson, 2006; Schellinck, Stanford, \& Darrah, 2003; Smith \& Zautra, 2008).

On the other hand, the intraperitoneal administration of diazepam significantly increased the number of open arm entries and the time spent on the open arm compared with those activities in the algesic-treated groups. These findings confirmed the anxiolytic activity of diazepam reported previously (Ishaq, 2014; Kilic, Ismailoglu, Kaygisiz, \& Oner, 2014; Kudagi, Kumar, \& Basha, 2012; Moreira et al., 2014). Diazepam acts on areas of the limbic system, thalamus, and hypothalamus inducing anxiolytic effects. It modulates HPA axis function during stress conditions thus reduces the level of plasma corticosterone in both animals and humans. So, diazepam is widely prescribed for the treatment of anxiety and as the standard drug (control) in many studies (Ishaq, 2014; Kudagi, Kumar, \& Basha, 2012).

Moreover, anxiety is thought to be associated with the intensity of pain. A possible mechanism for this result is that during transmission of nociceptive information to the central nervous system, sensory fibers transmit information by releasing excitatory amino acids such as glutamate or neuropeptides. Recent developments in the neurobiology of anxiety have highlighted the neurotransmitter glutamate as an important factor in anxiety and anxious behaviors. The effects of glutamate on anxiety related behaviors are mediated through different combinations of ionotropic and metabotropic glutamate receptors and potentially different subunit combinations (Gomperts, Carroll, Malenka, \& Nicoll, 2000).

Although the current study shows for the first time the pulpal pain-anxiety relationship in rats, other studies investigated the effects of other types of pain on anxiety. Van Wijk, Lindeboom, de Jongh, Tuk, \& Hoogstraten (2012) showed that the pain experience of a mandibular block is partly dependent on experienced anxiety. Moreover, it has been demonstrated that there is a relationship between reduced serotonin level and anxiety in arthritis pain model (Ernberg, Lundeberg, \& Kopp, 2000). Trigeminal neuralgia, temporomandibular joint disorder (Castro, Siqueira, Perissinotti, \& Siqueira, 2008), headache (Bishop, Holm, Borowiak, \& Wilson, 2001; Nash, Williams, Nicholson, \& Trask, 2006), and low back pain (Friedrich, Hahne, \& Wepner, 2009) are also accompanied by anxiety disorders. Patients who have can- cer or treatment-related pain are more likely to be anxious than cancer patients without pain (Thielking, 2003). Painrelated anxiety and acceptance of pain appear to be unique behavioral dimensions of adjustment to chronic pain (McCracken, Spertus, Janeck, Sinclair, \& Wetzel, 1999).

Amygdala has been shown to play a key role in fear and anxiety (Neugebauer, Li, Bird, \& Han, 2004; Zald \& Pardo, 1997). Pain signaling induces a regionally selective release of endogenous opioids bind to $\mu$-opioid receptors in the amygdala, which results in receptor internalization and recycling. Activation of $\mu$-opioid receptor is likely to play a major role in stressful conditions. The mentioned findings suggest the possibility that pain-induced changes in opioidergic function in the amygdala may lead to the anxiogenic effect.

The anterior cingulate cortex (ACC), which forms one of the largest parts of the limbic system, plays an important role in the affective component of pain. It has been reported that ACC modulates anxiety-like behavior in adult mice (Kim et al., 2011). Anatomically, the interconnections between the ACC and other limbic regions involved in pain modulation provide pathways through which ACC influences the emotional component of pain.

Zhong et al. (2012) addressed the role of ACC extracellular signal-regulated kinase (ERK) 1/2 in hypersensitivity and pain-related anxiety behavior in visceral pain. They suggested that ERK1/2 inhibitors represent potential therapeutic strategies for the treatment of pain-related anxiety disorders. Phosphorylation of ERK1/2 in ACC is implicated in the affective and sensory dimensions involved with inflammatory pain.

Another key finding was that treatment with diazepam 30 minutes before capsaicin injection showed a significant reduction in anxiety and pain. These results are in line with the findings of Hartford et al. (2008) reporting that more than half $(61 \%)$ of the patients seeking treatment and complained of significant pain, after anxiety treatment, reported an improvement of their pain symptoms. Rhudy and Meagher (2000) have also evaluated the effect of anxiety on pain reactivity in humans. The results of that study supported the fact that emotional states modulate human pain reactivity. In the field of dentistry, the anxiety level of the patient at the time of treatment has been shown to affect not only the patient's response to pain experienced during treatment but also the tendency of the patient to recall the experience as painful even 18 months after treatment (Aartman, de Jongh, Makkes, \& Hoogstraten, 2000). Simultaneous treatment of both pain and anxiety could result in a synergistic effect that will greatly help patients with pain by improving their quality of life. 
Current psychological theories suggest that attributional factors mediate the influence of anxiety on pain perception. According to the attribution theory, pain inhibition occurs when anxiety is unrelated to the pain-inducing event. On the other hand, an enhanced pain is expected when anxiety is related to the pain itself (Arntz, Dreessen, \& De Jong, 1994).

In addition to the interaction between pain and anxiety control regions in the nervous system, inflammatory factors such as IL-17, IL-6, TNF $\alpha$ (Liu, Ho, \& Mak, 2012), neurotransmitters like glutamate, GABA, serotonin, cholecystokinin (Clement, 1998; Cortese \& Phan, 2005; Daugé \& Léna, 1998; Domangue, Margolis, Lieberman, \& Kaji, 1985; Ernberg, Lundeberg, \& Kopp, 2000; Nemeroff, 2003; Rotzinger \& Vaccarino, 2003) and nerve growth factors like TNFo and brain-derived neurotrophic factor (BDNF) (Cirulli \& Alleva, 2009; Russo-Neustadt, Ha, Ramirez, \& Kesslak, 2001) play an important role in creating anxiety responses.

Rearing is considered to reflect exploratory activity, whereas grooming is correlated with emotionality (Archer, 1973; Barros, Tannhauser, Tannhauser, \& Tannhauser, 1994; Spasojevic, Gavrilovic, Varagic, \& Dronjak, 2007). In the present study, animals receiving nociceptive stimuli or chemical algesics did not present significant changes in these parameters. The results suggest that administration of capsaicin or formalin increases anxiety without modifying emotionality and exploratory activities. On the other hand, improper handling of the animals causes changes of mood that enhances animal's escape activities, including rearing (Szegedi et al., 2005). So, lack of changes in rearing activity in our study, confirms the appropriate handling of the animals during the test.

Caveats to the present findings should be mentioned. Although animal models of anxiety disorder have been useful in elucidating links between behavioral symptoms and biological abnormalities and in suggesting possible treatment strategies for the disease, the type of pain administered in this experiment, is not exactly comparable to the pulpal pain experience assessed in humans. Other factors that might have influenced the response to pain in humans should be also taken into consideration.

Based on the results in the elevated plus maze test, it was concluded that, inflammatory pulpal pain has an anxiogenic effect in rats, whereas diazepam premedication showed both anxiolytic and pain reducing effects.

\section{References}

Aartman, I. H. A., de Jongh, A., Makkes, P. C., \& Hoogstraten, J. (2000). Dental anxiety reduction and dental attendance after treatment in a dental fear clinic: A follow-up study. Community Dentistry and Oral Epidemiology, 28(6), 435-442. doi: 10.1034/j.16000528.2000.028006435.x

Archer, J. (1973). Tests for emotionality in rats and mice: A review. Animal Behaviour, 21(2), 205-235. doi: 10.1016/s00033472(73)80065-x

Arnold, L. M., Leon, T., Whalen, E., \& Barrett, J. (2010). Relationships Among Pain and Depressive and Anxiety Symptoms in Clinical Trials of Pregabalin in Fibromyalgia. Psychosomatics, 51(6), 489497. doi: 10.1016/s0033-3182(10)70741-6

Arntz, A., Dreessen, L., \& De Jong, P. (1994). The influence of anxiety on pain: attentional and attributional mediators. Pain, 56(3), 307314. doi: 10.1016/0304-3959(94)90169-4

Barros, H. M. T., Tannhauser, S. L., Tannhauser, M. A. L., \& Tannhauser, M. (1994). The Effects of GABAergic Drugs on Grooming Behaviour in the Open Field. Pharmacology \& Toxicology, 74(4-5), 339-344. doi: 10.1111/j.1600-0773.1994.tb01370.x

Beesdo, K., Jacobi, F., Hoyer, J., Low, N. C., Hofler, M., \& Wittchen H. U. (2010). Pain associated with specific anxiety and depressive disorders in a nationally representative population sample. Social Psychiatry and Psychiatric Epidemiology, 45(1), 89-104. doi: 10.1007/ s00127-009-0045-1

Bishop, K. L., Holm, J. E., Borowiak, D. M., \& Wilson, B. A. (2001) Perceptions of Pain in Women With Headache: A Laboratory Investigation of the Influence of Pain-Related Anxiety and Fear. Journal of Head and Face Pain, 41(5), 494-499. doi: 10.1046/j.15264610.2001.01087.x

Boleta-Ceranto, D. D. C. F., Bianchi, F. J., Miura, C. S. N., Veiga, M. C F., \& Bremm, L. L. (2010). Influence of orofacial pain, in superficial and deep tissue, on the anxiety levels in rats. Revista Odonto Ciência (Online), 25(4), 376-381. doi: 10.1590/s1980-65232010000400010

Castro, A. R., Siqueira, S. R. D. T., Perissinotti, D. M. N., \& Siqueira, J. T. T. (2008). Psychological evaluation and cope with trigeminal neuralgia and temporomandibular disorder. Arquivos de NeuroPsiquiatria, 66(3), 716-719. doi: 10.1590/s0004-282×2008000500021

Chidiac, J. J., Rifai, K., Hawwa, N. N., Massaad, C. A., Jurjus, A. R., Jabbur, S. J., et al. (2002). Nociceptive behaviour induced by dental application of irritants to rat incisors: A new model for tooth inflammatory pain. European Journal of Pain, 6(1), 55-67. doi: 10.1053/ eujp.2001.0305

Cirulli, F., \& Alleva, E. (2009). The NGF saga: From animal models of psychosocial stress to stress-related psychopathology. Frontiers in Neuroendocrinology, 30(3), 379-395. doi: 10.1016/j.yfrne.2009.05.002

Clavelou, P., Dallel, R., Orliaguet, T., Woda, A., \& Raboisson, P. (1995). The orofacial formalin test in rats: Effects of different formalin concentrations. Pain, 62(3), 295-301. doi: 10.1016/0304 3959(94)00273-h

Clement, Y. (1998). Biological bases of anxiety. Neuroscience $\mathcal{E}$ Biobehavioral Reviews, 22(5), 623-633. doi: 10.1016/s0149-7634(97)00058-4.

Cortese, B. M., \& Phan, K. L. (2005). The role of glutamate in anxiety and related disorders. CNS Spectrums, 10(10), 820-830. 
Daugé, V., \& Léna, I. (1998). CCK in Anxiety and Cognitive Processes. Neuroscience \& Biobehavioral Reviews, 22(6), 815-825. doi: 10.1016/s0149-7634(98)00011-6

Deng, G., \& Cassileth, B. R. (2005). Integrative Oncology: Complementary Therapies for Pain, Anxiety, and Mood Disturbance. A Cancer Journal for Clinicians, 55(2), 109-116. doi: 10.3322/canjclin.55.2.109

Domangue, B. B., Margolis, C. G., Lieberman, D., \& Kaji, H. (1985). Biochemical correlates of hypnoanalgesia in arthritic pain patients. Journal of Clinical Psychiatry, 46(6), 235-8.

Dubuisson, D., \& Dennis, S. G. (1977). The formalin test: A quantitative study of the analgesic effects of morphine, meperidine, and brain stem stimulation in rats and cats. Pain, 4, 161-174. doi: 10.1016/0304-3959(77)90130-0

Ennaceur, A., Michalikova, S., \& Chazot, P. L. (2006). Models of anxiety: Responses of rats to novelty in an open space and an enclosed space. Behavioural Brain Research, 171(1), 26-49. doi: 10.1016/j. bbr.2006.03.016

Ernberg, M., Lundeberg, T., \& Kopp, S. (2000). Pain and allodynia/ hyperalgesia induced by intramuscular injection of serotonin in patients with fibromyalgia and healthy individuals. Pain, 85(1), 3139. doi: 10.1016/s0304-3959(99)00233-x

Fried, K., Lillesaar, C., Sime, W., Kaukua, N., \& Patarroyo, M. (2007). Target finding of pain nerve fibers: Neural growth mechanisms in the tooth pulp. Physiology \& Behavior, 92(1-2), 40-45. doi: 10.1016/j. physbeh.2007.05.032

Friedrich, M., Hahne, J., \& Wepner, F. (2009). A Controlled Examination of Medical and Psychosocial Factors Associated With Low Back Pain in Combination With Widespread Musculoskeletal Pain. Physical Therapy, 89(8), 786-803. doi: 10.2522/ptj.20080100

Gomperts, S. N., Carroll, R., Malenka, R. C., \& Nicoll, R. A. (2000). Distinct roles for ionotropic and metabotropic glutamate receptors in the maturation of excitatory synapses. Journal of Neuroscience, 20(6), 2229-2237.

Hartford, J. T., Endicott, J., Kornstein, S. G., Allgulander, C., Wohlreich, M. M., Russell, J. M., et al. (2008). Implications of Pain in Generalized Anxiety Disorder. Primary Care Companion to The Journal of Clinical Psychiatry, 10(03),197-204. doi:10.4088/pcc.v10n0304

Ishaq, H. (2014). Anxiolytic Effect of Herbal medicine, Khamira Gaozaban Ambri Jadwar Ood Salib Wala (KGJ) in experimental rat models. Pakistan Journal of Pharmaceutical Sciences, 27(2), 289-294.

Kilic, F. S., Ismailoglu, S., Kaygisiz, B., \& Oner, S. (2014). Effects of single and combined gabapentin use in elevated plus maze and forced swimming tests. Acta Neuropsychiatrica, 26(5), 307-314. doi: 10.1017/neu.2014.17

Kim, S. S., Wang, H., Li, X. Y., Chen, T., Mercaldo, V., Descalzi, G., et al. (2011). Neurabin in the anterior cingulate cortex regulates anxiety-like behavior in adult mice. Molecular Brain, 4(1), 6. doi: 10.1186/1756-6606-4-6

Kizilbash, A. H., Vanderploeg, R. D., \& Curtiss, G. (2002). The effects of depression and anxiety on memory performance. Archives of Clinical Neuropsychology, 17(1), 57-67. doi: 10.1093/arclin/17.1.57

Kudagi, B., Kumar, R. P., \& Basha, S. S. (2012). Evaluation of AntiAnxiety, Sedative and Motor Co-Ordination Properties of Ganaxolone in Comparison with Diazepam in Rodent Models. Journal of Dental and Medical Sciences, 1(4), 42-47. doi: 10.9790/0853-0144247
Kuijpers, P. M. J. C., Denollet, J., Lousberg, R., Wellens, H. J. J., Crijns, H., \& Honig, A. (2003). Validity of the Hospital Anxiety and Depression Scale for Use With Patients With Noncardiac Chest Pain. Psychosomatics, 44(4), 329-335. doi: 10.1176/appi.psy.44.4.329

Lipton, J., Ship, J., \& Larach-Robinson, D. (1993). Estimated Prevalence and Distribution of Reported Orofacial Pain in the United States. Journal of the American Dental Association, 124(10), 115-125. doi: 10.14219/jada.archive.1993.0200

Liu, Y., Ho, R. C., \& Mak, A. (2012). The role of interleukin (IL)-17 in anxiety and depression of patients with rheumatoid arthritis. International Journal of Rheumatic Diseases, 15(2), 183-187. doi: 10.1111/j.1756-185X.2011.01673.x

Martin, P. R., \& MacLeod, C. (2009). Behavioral management of headache triggers: Avoidance of triggers is an inadequate strategy. Clinical Psychology Review, 29(6), 483-495. doi: 10.1016/j. cpr.2009.05.002

McCracken, L. M., Faber, S. D., \& Janeck, A. (1998). Pain-related anxiety predicts non-specific physical complaints in persons with chronic pain. Behaviour Research and Therapy, 36(6), 621-630. doi: 10.1016/s0005-7967(97)10039-0

McCracken, L. M., Spertus, I. L., Janeck, A. S., Sinclair, D., \& Wetzel, T. F. (1999). Behavioral dimensions of adjustment in persons with chronic pain: pain-related anxiety and acceptance. Pain, 80(1), 283289. doi: 10.1016/s0304-3959(98)00219-x

Moreira, M. R. C., Salvadori, M. G. D. S. S., de Almeida, A. A. C. de Sousa, D. P., Jordán, J., Satyal, P., et al. (2014). Anxiolytic-like effects and mechanism of (-)-myrtenol: A monoterpene alcohol. Neuroscience Letters, 579, 119-124. doi: 10.1016/j.neulet.2014.07.007

Nash, J. M., Williams, D. M., Nicholson, R., \& Trask, P. C. (2006). The Contribution of Pain-Related Anxiety to Disability from Headache. Journal of Behavioral Medicine, 29(1), 61-67. doi: 10.1007/ s10865-005-9033-4

Nemeroff, C. B. (2003). The role of GABA in the pathophysiology and treatment of anxiety disorders. Psychopharmacology Bulletin $37(4), 133-146$

Neugebauer, V., Li, W., Bird, G. C., \& Han, J. S. (2004). The Amygdala and Persistent Pain. Neuroscientist, 10(3), 221-234. doi $10.1177 / 1073858403261077$

Oliveira, M. M. T., \& Colares, V. (2009). The relationship between dental anxiety and dental pain in children aged 18 to 59 months: a study in Recife, Pernambuco State, Brazil. Cadernos de Saúde Pública, 25(4), 743-750. doi: 10.1590/s0102-311×2009000400005

Pae, C. U., Masand, P. S., Marks, D. M., Krulewicz, S., Peindl, K. Mannelli, P., et al. (2009). History of depressive and/or anxiety disorders as a predictor of treatment response: A post hoc analysis of a 12-week, randomized, double-blind, placebo-controlled trial of paroxetine controlled release in patients with fibromyalgia. Progress in Neuro-Psychopharmacology and Biological Psychiatry, 33(6), 996-1002. doi: 10.1016/j.pnpbp.2009.05.005

Primeaux, S., Wilson, S., McDonald, A., Mascagni, F., \& Wilson, M. (2006). The role of delta opioid receptors in the anxiolytic actions of benzodiazepines. Pharmacology Biochemistry and Behavior, 85(3), 545-554. doi: 10.1016/j.pbb.2006.09.025

Raoof, M., Abbasnejad, M., Amirkhosravi, L., Ebrahimnejad, H., \& Raoof, R. (2012). A modification of a previous model for inflammatory tooth pain: Effects of different capsaicin and formalin concentrations and ibuprofen. Journal of Oral Health and Oral Epidemiology, 1(2), 70-77. 
Rhudy, J. L., \& Meagher, M. W. (2000). Fear and anxiety: Divergent effects on human pain thresholds. Pain, 84(1), 65-75. doi: 10.1016/ s0304-3959(99)00183-9

Rotzinger, S., \& Vaccarino, F. J. (2003). Cholecystokinin receptor subtypes: Role in the modulation of anxiety-related and rewardrelated behaviours in animal models. Journal of Psychiatry and Neuroscience, 28(3), 171.

Rozanski, A., Blumenthal, J. A., Davidson, K. W., Saab, P. G., \& Kubzansky, L. (2005). The epidemiology, pathophysiology, and management of psychosocial risk factors in cardiac practice. Journal of the American College of Cardiology, 45(5), 637-651. doi: 10.1016/j.jacc.2004.12.005

Russo-Neustadt, A., Ha, T., Ramirez, R., \& Kesslak, J. P. (2001). Physical activity-antidepressant treatment combination: impact on brain-derived neurotrophic factor and behavior in an animal model. Behavioural Brain Research, 120(1), 87-95. doi: 10.1016/ s0166-4328(00)00364-8

Schellinck, H. M., Stanford, L., \& Darrah, M. (2003). Repetitive acute pain in infancy increases anxiety but does not alter spatial learning ability in juvenile mice. Behavioural Brain Research, 142(1-2), 157165. doi: 10.1016/s0166-4328(02)00406-0

Smith, B. W., \& Zautra, A. J. (2008). The effects of anxiety and depression on weekly pain in women with arthritis. Pain, 138(2), 354-361. doi: $10.1016 / j . p a i n .2008 .01 .008$

Spasojevic, N., Gavrilovic, L., Varagic, V. V., \& Dronjak, S. (2007). Of chronic diazepam treatments on behavior on individually housed rats. Archives of Biological Sciences, 59(2), 113-117. doi: 10.2298/ abs0702113s

Szegedi, V., Bárdos, G., Détári, L., Tóth, A., Banczerowski-Pelyhe, I., \& Világi, I. (2005). Transient alterations in neuronal and behavioral activity following bensultap and fipronil treatment in rats. Toxicology, 214(1-2), 67-76. doi: 10.1016/j.tox.2005.05.023

Thielking, P. D. (2003). Cancer pain and anxiety. Current Pain and Headache Reports, 7(4), 249-261. doi: 10.1007/s11916-003-0045-x

van Wijk, A., Lindeboom, J. A., de Jongh, A., Tuk, J. G., \& Hoogstraten, J. (2012). Pain related to mandibular block injections and its relationship with anxiety and previous experiences with dental anesthetics. Oral Surgery, Oral Medicine, Oral Pathology and Oral Radiology, 114(5), S114-S119. doi: 10.1016/j.oooo.2011.08.006

Walf, A. A., \& Frye, C. A. (2007). The use of the elevated plus maze as an assay of anxiety-related behavior in rodents. Nature Protocols, 2(2), 322-328. doi: 10.1038/nprot.2007.44

Zald, D. H., \& Pardo, J. V. (1997). Emotion, olfaction, and the human amygdala: Amygdala activation during aversive olfactory stimulation. Proceedings of the National Academy of Sciences, 94(8), 4119-4124. doi: 10.1073/pnas.94.8.4119

Zhong, X. L., Wei, R., Zhou, P., Luo, Y. W., Wang, X. Q., Duan, J., et al. (2012). Activation of Anterior Cingulate Cortex Extracellular Signal-Regulated Kinase-1 and -2 (ERK1/2) Regulates Acetic Acid-Induced, Pain-Related Anxiety in Adult Female Mice. Acto Histochemica et Cytochemica, 45(4), 219-225. doi: 10.1267/ahc.12002 
